\title{
Application of High-Frequency Induction Heating Apparatus to Heat Treatment of 6061 Aluminum Alloy*
}

\author{
Fang-ni Shang $^{1}$, Eiji Sekiya ${ }^{2}$ and Yoshihiro Nakayama ${ }^{3}$ \\ ${ }^{1}$ Science Education Department, Interdisciplinary Graduate School of Medicine and Engineering, \\ University of Yamanashi, Kofu 400-8511, Japan \\ ${ }^{2}$ Research and Design Department, YS Electronics Co., Ltd., Kofu 400-0043, Japan \\ ${ }^{3}$ Science Research Department, Interdisciplinary Graduate School of Medicine and Engineering, \\ University of Yamanashi, Kofu 400-8511, Japan
}

\begin{abstract}
A high-frequency induction heating apparatus was used for the heat treatment of a commercial 6061 aluminum alloy bar with the objective of improving the mechanical properties and productivity. Heating states of the 6061 alloy bar were examined in terms of temperature distribution, heating rate, overheating and temperature fluctuation; moreover, the mechanical properties of the alloy after heat treatment were also investigated. The results of this study are as follows. When the 6061 alloy bar was rapidly heated to the heat treatment temperature using the induction heating apparatus, temperature distribution and overheating of the sample were small as well as the temperature fluctuations in the holding process. A rapid heating rate of about $21^{\circ} \mathrm{C} / \mathrm{s}$ heated the sample to the heat treatment temperature of $560^{\circ} \mathrm{C}$ in $26 \mathrm{~s}$. The sample showed equivalent or superior mechanical properties compared with a sample heated by conventional electric furnace. Temperature and time of the heat treatment process greatly influenced the mechanical properties of the 6061 alloy, while there was no significant difference in mechanical properties of the sample heat-treated at various heating rates. [doi:10.2320/matertrans.L-M2011825]
\end{abstract}

(Received September 30, 2010; Accepted August 20, 2011; Published October 13, 2011)

Keywords: induction heating, 6061 aluminum alloy, heat treatment, rapid heating

\section{Introduction}

Heat-treatable aluminum alloys must be solution-treated to increase their strength. An electric furnace (EF) is widely used for solution-treating these alloys due to ease of operation and equipment. However, the temperature controllability and energy efficiency of the EF are poor. Hightemperature solution treatment saves time in the heat treatment process, increases productivity and improves mechanical properties as it increases the amount of solid solution atoms. ${ }^{1)}$ To realize high-temperature solution treatment, it is important to ensure rapid heating, no overheating during the temperature transition state from rising to holding, and stability of temperature in the holding process. Induction heating $(\mathrm{IH})$ is also widely used for industrial applications due to its advantages of rapid heating, good controllability of temperature and energy savings. Microstructure control and mechanical properties of induction-heated and subsequently quenched carbon steel have been reported. ${ }^{2)}$ Komotori et al. studied the fatigue strength of super-rapid induction-heated and quenched steel. ${ }^{3-5)}$ The tensile and fatigue strength of titanium alloy were improved by short-time induction heat treatment. ${ }^{6,7)}$ Studies on continuous processing of aluminum alloys for sheet products reported significant grain refinement from $50-70 \mu \mathrm{m}$ to $10-20 \mu \mathrm{m}$ by rapid heating. ${ }^{8,9)}$ However, there have been few reports on the induction heating of bulk aluminum alloys.

In the present study, we used an induction heating apparatus to heat treatment of heat-treatable aluminum alloys. Temperature profiles in the heat treatment process in terms of heating rate, overheating and temperature

*The Paper Contains Partial Overlap with the ICAA12 Proceedings by USB under the Permission of the Editorial Committee. fluctuations were measured for commercial 6061 aluminum alloys. In general, the frequency of an induction heating apparatus for homogeneous heating of large-scale samples is less than $400 \mathrm{kHz}$, whereas a higher frequency is recommended for effective heating of small-scale products as well as local heating of industrial products. ${ }^{10)}$ In this study, a newly developed induction heating apparatus with a frequency of $2 \mathrm{MHz}$ was used for the heat treatment of a 6061 alloy bar with a diameter of $10 \mathrm{~mm}$ and length of $150 \mathrm{~mm}$. In induction heating, the temperature cannot be measured using a conventional thermocouple due to the magnetic field generated by the heating coil. Furthermore, temperature measurement using a radiation thermometer is difficult due to the unstable emissivity of aluminum alloys. Our previous study ${ }^{11)}$ investigated the effect of surface conditions on temperature measurement using a radiation thermometer and found that temperature could be precisely measured by spraying the sample surface with a black coating.

In this paper we examined the heating states of a 6061 aluminum alloy bar in a rapid heating process using an induction heating apparatus. In addition, the mechanical properties of the induction-heated 6061 aluminum alloy were systematically investigated in terms of temperature, time and heating rate in the heat treatment process. The results were compared with those obtained using samples heated by a conventional electric furnace. Based on these results, we examined the feasibility of using the induction heating apparatus for the heat treatment of heat-treatable aluminum alloys.

\section{Experimental}

Commercial A6061-T6 aluminum alloy bar $(10 \mathrm{~mm}$ in diameter, $150 \mathrm{~mm}$ in length) fabricated by extrusion was used 


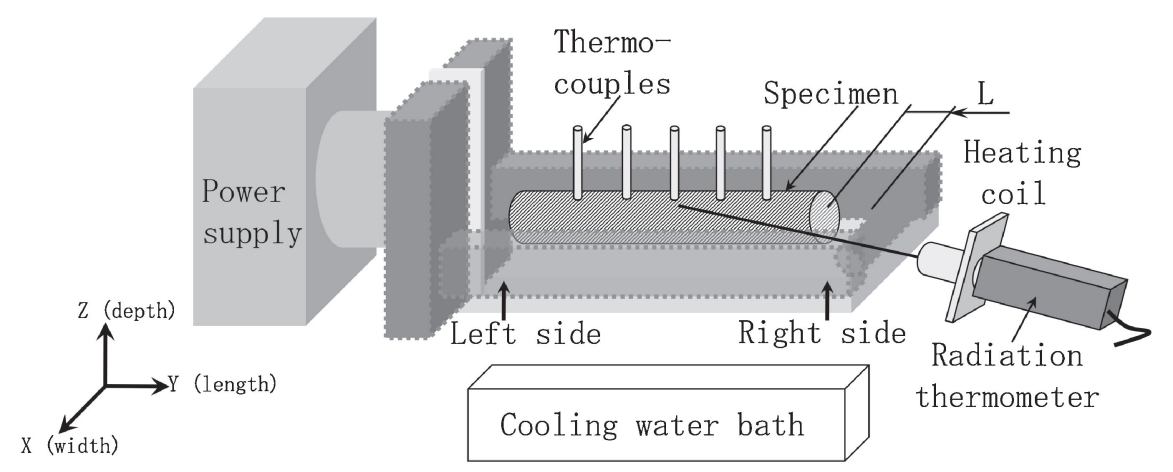

Fig. 1 Schematic diagram of experimental apparatus.

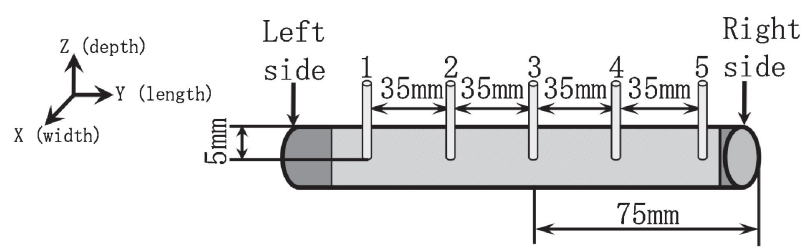

(a)

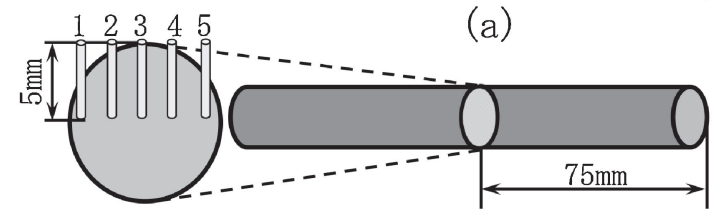

(b)

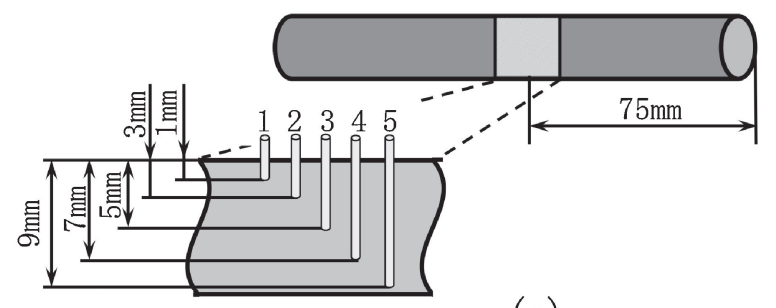

(c)

Fig. 2 Detailed schematic illustration showing thermocouple location in length (a), width (b) and depth direction (c).

in this study. Figure 1 is a schematic diagram showing the arrangement of the specimen, induction heating coil, radiation thermometer and cooling water bath. The frequency and power of the induction heating apparatus are $2 \mathrm{MHz}$ and $10 \mathrm{~kW}$, respectively. The surface of the sample was sprayed with a black coating to ensure precision temperature measurement using a radiation thermometer with a measurable temperature range of more than $250^{\circ} \mathrm{C}$. The radiation thermometer measured the temperature at the center of the sample. To investigate the temperature distribution in the sample immediately after the heating process, five thermocouples (type $\mathrm{K}$ ) were positioned in the length, width and depth directions. A detailed schematic diagram of the thermocouple locations is shown in Fig. 2. Differential scanning calorimetry analysis (DSC) was conducted using a Seiko Instruments DSC220 at a heating rate of $10^{\circ} \mathrm{C} / \mathrm{min}$ for a sample weighing $10 \mathrm{mg}$. The upper limit of the heat treatment temperature was set at $590^{\circ} \mathrm{C}$ based on the solidus temperature of $596^{\circ} \mathrm{C}$ estimated from the DSC results. On the other hand, the lower limit of the temperature was chosen at $260^{\circ} \mathrm{C}$. From this heat treatment with a wide range of

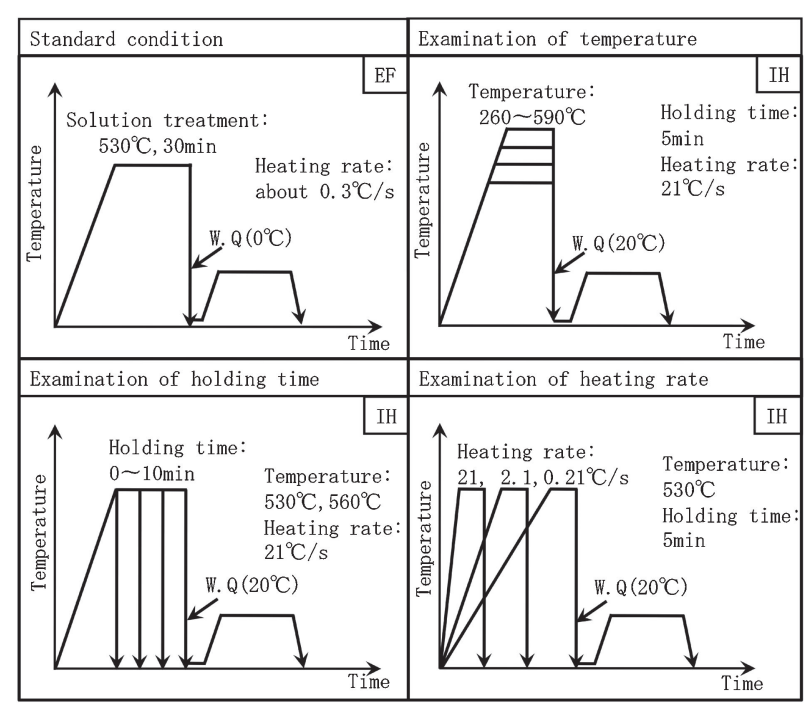

Fig. 3 Summary of heat treatment conditions.

temperature, the microstructural change related to the precipitation or the solution behaviors during heat treatment may be easily understood. In the present study, temperature, time and heating rate in the heat treatment process were also systematically varied to investigate the effect of the heat treatment conditions on the mechanical properties. The heat treatment conditions are summarized in Fig. 3. It should be noted that the heat treatment at temperatures above $400^{\circ} \mathrm{C}$ in this study essentially means re-solution treatment since the sample was already heat treated in the T6 state. On the other hand, that at temperatures less than $400^{\circ} \mathrm{C}$ may result in the coarsening of precipitates, which corresponds to over-aging treatment. After the heat treatment, the samples were quenched in water at $20^{\circ} \mathrm{C}$ located below the sample. After quenching, the samples were naturally aged for $48 \mathrm{~h}$ at room temperature (T4). One of them was artificially aged at $180^{\circ} \mathrm{C}$ for $8 \mathrm{~h}$ using an EF apparatus (T6). For comparison, heat treatment was also conducted using an EF apparatus under the standard solution treatment conditions $\left(530^{\circ} \mathrm{C}\right.$ for $30 \mathrm{~min})$. Vickers microhardness test, tensile test, electrical conductivity measurement and microstructure observation were performed after natural/artificial aging. Vickers microhardness was measured at a load of $100 \mathrm{~g}$ at a holding time of $15 \mathrm{~s}$. The tensile test specimen was prepared following the JIS-14A standard (diameter $6.0 \mathrm{~mm}$, gauge length $30 \mathrm{~mm}$ ) 


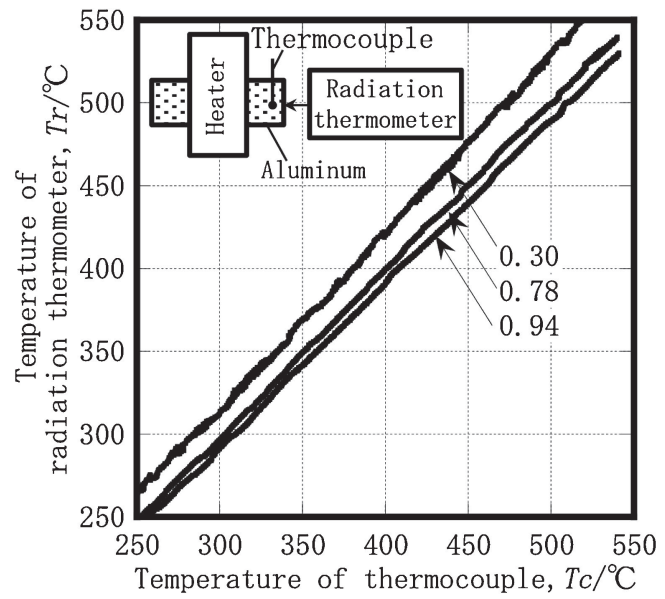

Fig. 4 Effect of emissivity on temperature measurement for aluminum sample with black coating.

and subjected to the tensile test at a constant crosshead speed of $1.0 \mathrm{~mm} / \mathrm{min}$ at room temperature. Electrical conductivity was measured using a digital electrical conductivity meter (Autosigma 2000). Samples for optical microscopy observation were prepared by the anodic oxidation method. A scanning electron microscope operated at $15 \mathrm{kV}$ (Hitachi S-4500) was used for observing the fracture surface.

\section{Results and Discussion}

\subsection{Temperature distribution in sample}

The effect of emissivity on the accuracy of temperature measurement using a radiation thermometer was investigated for the aluminum sample with a black body and the results were as shown in Fig. 4. A thermocouple was inserted into the sample to a depth of $0.2 \mathrm{~mm}$ from the surface, and the radiation thermometer measured the surface temperature of the sample simultaneously. When the temperature measured by the radiation thermometer matched that of the thermocouple, the emissivity value was considered to be the proper measurement value. The temperature measured using the emissivity value of 0.78 is in good agreement with that of the thermocouple, as seen in Fig. 4. From this result, the emissivity value of 0.78 was adopted for the temperature measurement using a radiation thermometer. Incidentally, the distance $L$ between the sample edge and the heating coil (see Fig. 1) is thought to significantly influence the temperature distribution in the length direction of the sample because the magnetic field strength varies with the location of the sample in the induction heating coil. Figure 5 shows the changes in temperature distribution in the length direction with distance $L$ (a), and those in the width and depth directions (b). Temperature was measured when the temperature of the specimen surface measured by the radiation thermometer reached $560^{\circ} \mathrm{C}$ and the heating coil was turned off. The value on the $y$-axis shows the temperature differences of each channel against that of channel 3 (see Fig. 2). As shown in Fig. 5(a), the maximum difference appeared at $L=0 \mathrm{~mm}$ and $30 \mathrm{~mm}$. The temperature of channel 5 showed the highest value at $L=0 \mathrm{~mm}$ and the lowest value at $L=30 \mathrm{~mm}$. These temperature distributions indicate that the magnetic field (a)

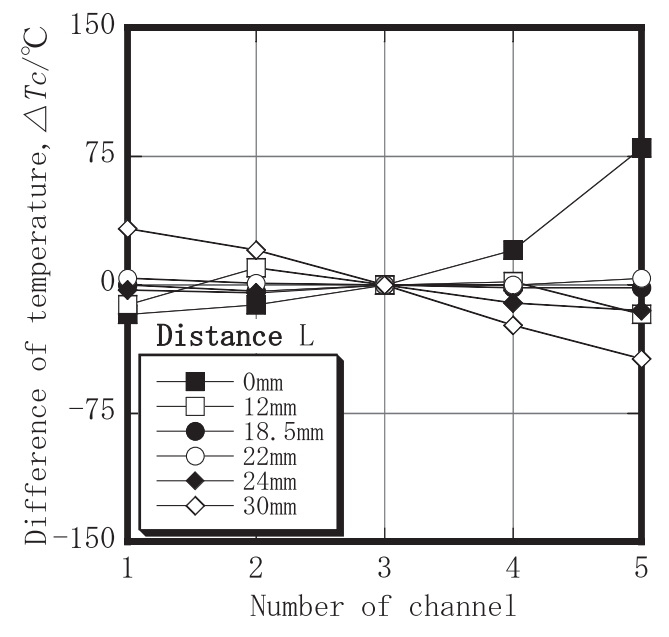

(b)

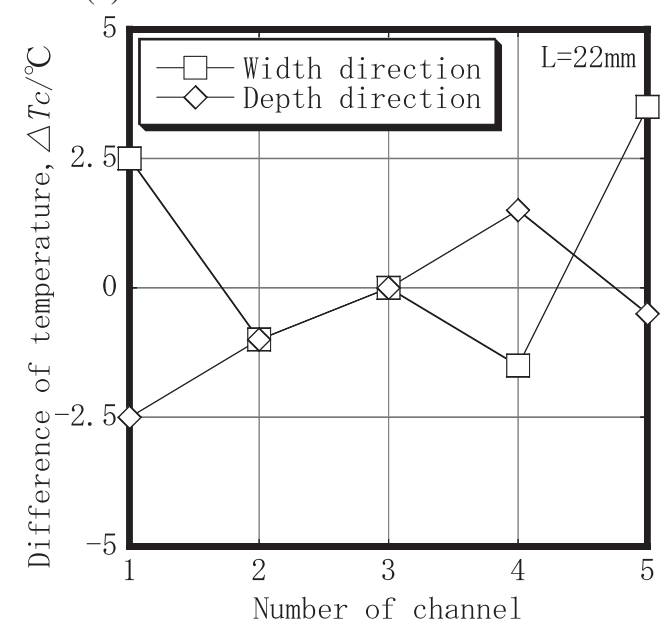

Fig. 5 Changes in the temperature difference of five thermometers in the length direction with the distance $L$ (a), and those in the width and depth directions (b). The value on the $y$-axis shows the temperature difference of each channel against that of channel 3 .

strength is high at either side of the heating coil. Since the minimum difference in temperature of less than $3^{\circ} \mathrm{C}$ was obtained at $L=18.5$ or $22.0 \mathrm{~mm}$, the following experiments were conducted using either $L$ value. In addition, the temperature differences in the width and depth directions were measured and are shown in Fig. 5(b). It can be seen that the temperature distribution in the width and depth directions is small within the range of $3.5^{\circ} \mathrm{C}$. Generally speaking, eddy currents induced by induction heating apparatus are concentrated on the surface layers facing the heating coil and heat generation may have occurred mainly in these surface layers (skin effect). The current penetration depth of the skin effect is dependent on the electrical and magnetic properties of the material and the frequency of the induction heating apparatus. ${ }^{10)}$ The calculated current penetration depth is estimated at about $71 \mu \mathrm{m}$. Although the regions of heat generation were thin, homogeneous heating was achieved in the length, width and depth directions. It is considered that this homogeneous heating status is derived from the good thermal conductivity of the aluminum alloys as well as the small sample size. 


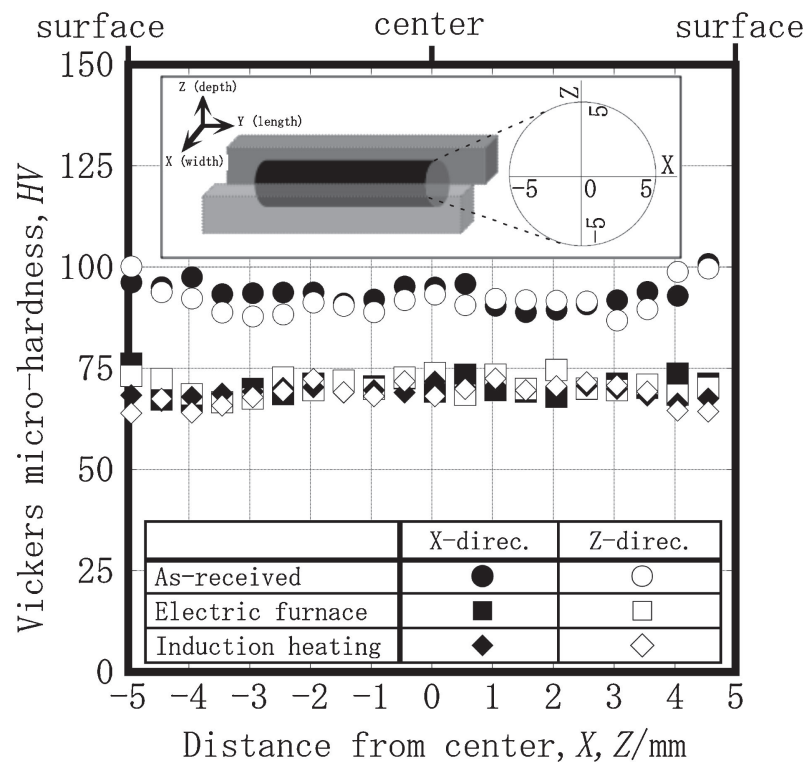

Fig. 6 Vickers microhardness distribution for samples heat-treated by induction heating (heating rate: $21^{\circ} \mathrm{C} / \mathrm{s}$ ) and electric furnace (heating rate: approximately $0.3^{\circ} \mathrm{C} / \mathrm{s}$ ). Heat treatment was carried out at $530^{\circ} \mathrm{C}$ for $5 \mathrm{~min}$ (IH) and $30 \mathrm{~min}(\mathrm{EF})$. Inset shows a schematic illustration of the measurement direction and position.

To confirm the effect of temperature distribution existing in the sample, the hardness distribution was measured in the width and depth directions after heat treatment. Figure 6 shows the Vickers microhardness distribution for the sample heat-treated by the IH apparatus (heating rate: $21^{\circ} \mathrm{C} / \mathrm{s}$ ) and by the $\mathrm{EF}$ apparatus (heating rate: approximately $0.3^{\circ} \mathrm{C} / \mathrm{s}$ ). The samples were subjected to heat treatment at $530^{\circ} \mathrm{C}$ for $5 \mathrm{~min}(\mathrm{IH})$ and $30 \mathrm{~min}(\mathrm{EF})$, and then quenched in water. In Fig. 6, the hardness distribution of an as-received sample is also shown for reference. The inset in the figure shows a schematic illustration indicating the measurement direction and position of hardness. Hardness values in the width and depth directions show almost the same values for the induction-heated samples, suggesting no remarkable temperature distribution during the heat treatment. Moreover, the hardness distribution of the sample heat-treated by the EF apparatus is equivalent to that by the IH apparatus. The average hardness values of the as-received sample and the samples heat-treated by the EF and the IH apparatus were 93, 71 and $69 \mathrm{HV}$, respectively. The decrease in hardness from 93 to about $70 \mathrm{HV}$ is considered to be due to the disappearance of precipitates during the heat treatment process. Since the hardness value of the sample heated by the IH apparatus is equivalent to that heated by the EF, the microstructures of the two samples may be almost the same.

It was also important to examine the heating characteristics of each heating apparatus. Figure 7 shows the representative temperature profiles and heating rates for the IH (a) and the EF (b) together with those of the salt bath (c). An enlargement of the temperature profile immediately after the completion of temperature rise is inserted for the $\mathrm{IH}$. In the case of $\mathrm{IH}$, the linear rise in temperature up to the heat treatment temperature was obtained by keeping the heating rate at a constant value of about $21^{\circ} \mathrm{C} / \mathrm{s}$ (a). Moreover, the overheating generated during the temperature transition stage from rising to holding processes was about $4^{\circ} \mathrm{C}$ and the temperature fluctuation in the holding process was about $\pm 2^{\circ} \mathrm{C}$. On the other hand, the heating rate of the EF must be kept below $0.1^{\circ} \mathrm{C} / \mathrm{s}$ to avoid marked overheating (b), so a long time is needed for the temperature to reach the target temperature. Moreover, a relatively large temperature fluctuation in the holding process results from the indirect heating of the EF apparatus. The heating rate of the salt bath showed a remarkable value exceeding $60^{\circ} \mathrm{C} / \mathrm{s}$ in the early stage of the heating process but decreased markedly in the latter stage; hence, the temperature difference between the salt and the sample is small (c). It was difficult to control the temperature of the sample during the heating and holding processes because the salt was kept at a constant temperature. These results suggest that the induction heating apparatus possesses excellent heating characteristics compared with the electric furnace and the salt bath.

\subsection{Effect of heat treatment temperature}

Here, we describe the effect of the heat treatment temperature on the mechanical properties after the sample was heat treated using the $\mathrm{IH}$ apparatus at a rapid heating rate of $21^{\circ} \mathrm{C} / \mathrm{s}$. Figure 8 shows the temperature profile for various heat treatment temperatures from $260^{\circ} \mathrm{C}$ to $590^{\circ} \mathrm{C}$. The temperature at the sample surface (near the center in the length direction, as shown in Fig. 1) was measured using the radiation thermometer. Since the measurable lower limit temperature of the radiation thermometer is $250^{\circ} \mathrm{C}$, temperatures above $250^{\circ} \mathrm{C}$ are shown in Fig. 8. A linear rise in temperature $\left(21^{\circ} \mathrm{C} / \mathrm{s}\right)$ up to the heat treatment temperature in the heating process and small-scale overheating $\left(2-4^{\circ} \mathrm{C}\right)$ during the temperature transition stage from heating to holding processes (except for $260^{\circ} \mathrm{C}$ ) were achieved. There was no significant temperature fluctuation $\left( \pm 3^{\circ} \mathrm{C}\right)$ in the holding process. These temperature profiles show that the heat treatment at various temperatures using the induction heating apparatus was processed properly. The hardness obtained after T4 and T6 treatments at various heat treatment temperatures is shown in Fig. 9. There is a great variation in hardness at a heat treatment temperature of $440^{\circ} \mathrm{C}$ for the $\mathrm{T} 4$ and T6 treatments. In the case of T4 treatment, when heat treatment was carried out below $380^{\circ} \mathrm{C}$, the hardness decreased with the increase in heat treatment temperature. On the other hand, the hardness increased after heat treatment at temperatures above $440^{\circ} \mathrm{C}$. This decrease in hardness may be the result of a growth in precipitates, while the increase in solid solute atoms such as $\mathrm{Mg}$ and $\mathrm{Si}$ with rising heat treatment temperature may have caused the increase in hardness. In relation to this, the artificial aging treatment led to a significant increase in hardness for the samples heated at temperatures above $440^{\circ} \mathrm{C}$. The hardness change shown in Fig. 9 clearly indicates that heating temperatures below $380^{\circ} \mathrm{C}$ are over-aging treatment whereas those above $440^{\circ} \mathrm{C}$ are solution treatment. There is a report ${ }^{12)}$ describing that the nose temperature of a 6061 aluminum alloy is about $380^{\circ} \mathrm{C}$. Therefore, it is considered that the rapid heating has no significant effect on the phase decomposition of this alloy. Incidentally, the samples heated by the EF apparatus show hardness values of $70 \mathrm{HV}$ (T4 conditions) and 100 HV (T6 
(a)

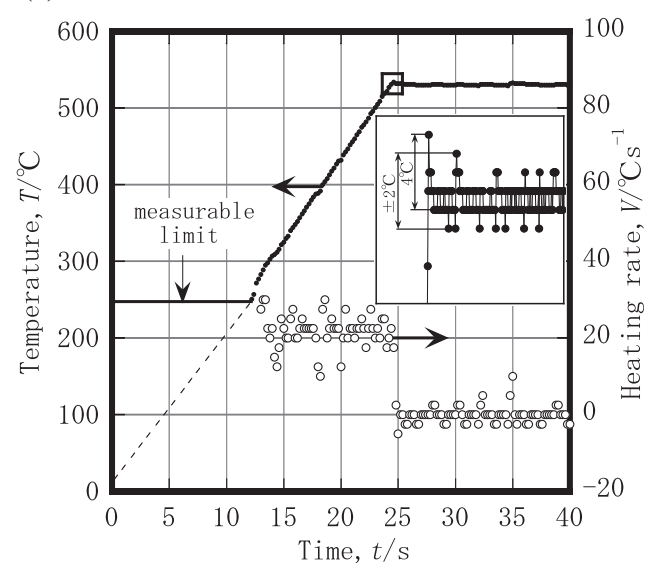

(b)

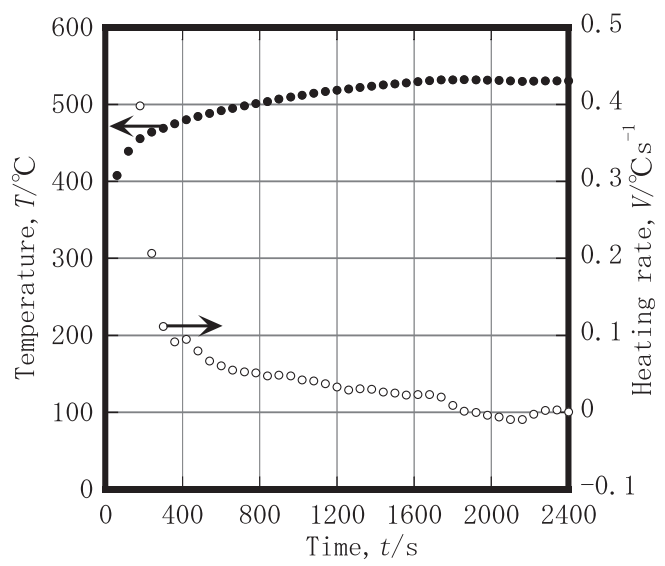

(c)

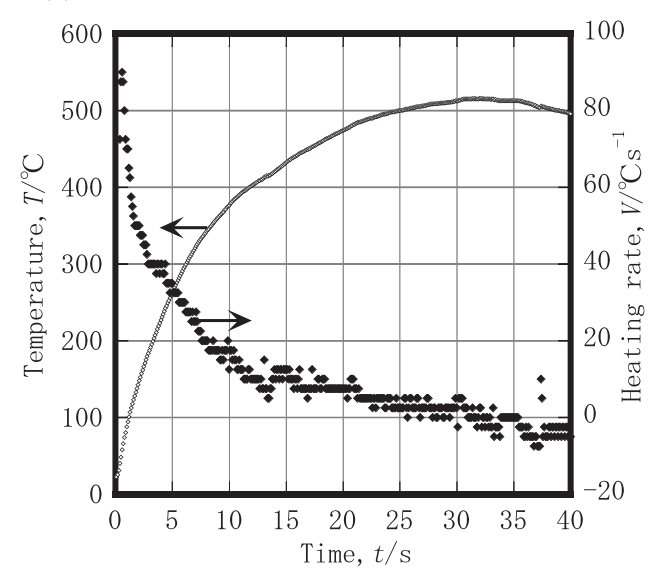

Fig. 7 Temperature profiles and heating rates for induction heating (a), electric furnace (b) and salt bath (c), respectively. The inserted diagram in Fig. 7(a) shows the temperature profile immediately after the completion of temperature rise to the heat treatment temperature. The measurement location for the radiation thermometer was the center of the sample (near channel 3, see Fig. 2) and the measurable limit was above $250^{\circ} \mathrm{C}$ under specification.

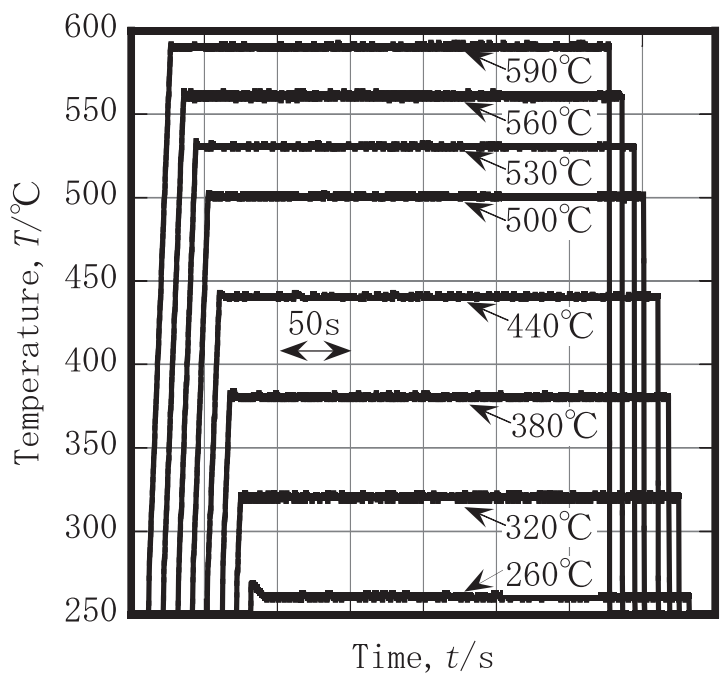

Fig. 8 Temperature profiles for various heat treatment temperatures from 260 to $590^{\circ} \mathrm{C}$

conditions), which are identical to those of samples heated by the $\mathrm{IH}$ apparatus at $530^{\circ} \mathrm{C}$. Because these samples were treated by different heating rate and holding time, it is not reasonable to evaluate the effect of heating rate and holding

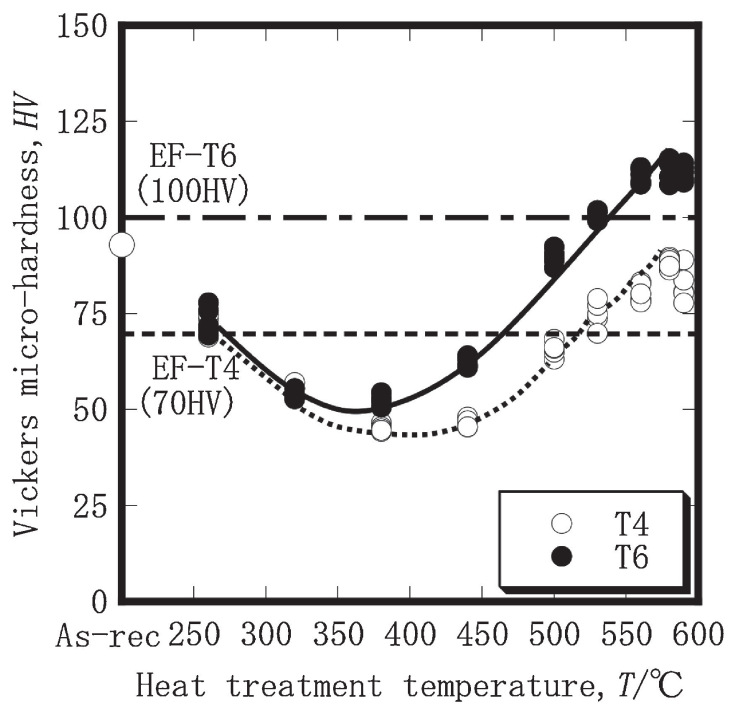

Fig. 9 Hardness obtained after T4 and T6 treatment for various heat treatment temperatures.

time on the hardness based on these measured hardness values.

Figure 10 shows the variation in the $0.2 \%$ proof stress with the heat treatment temperature. The change is almost 


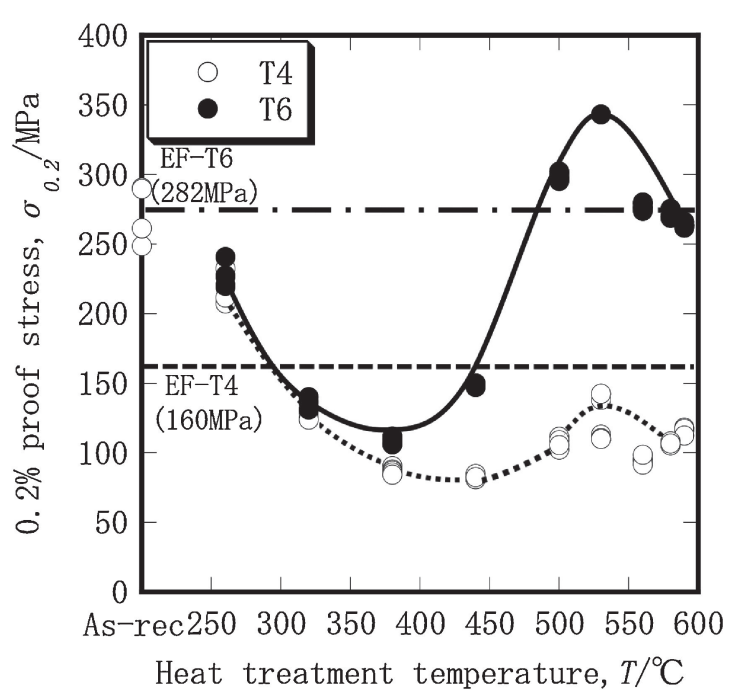

Fig. 10 Variations in $0.2 \%$ proof stress with heat treatment temperature.

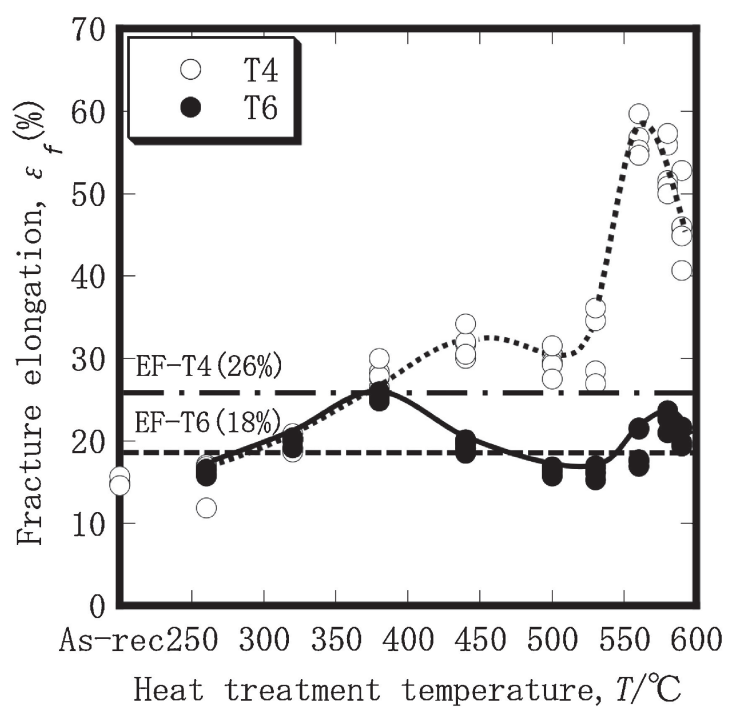

Fig. 11 Fracture elongation for each heat treatment temperature.

equivalent to that of the hardness shown in Fig. 9. The $0.2 \%$ proof stress after T4 and T6 treatment increased for heat treatment temperatures above $440^{\circ} \mathrm{C}$, showing a peak value at $530^{\circ} \mathrm{C}$ and then decreasing. The increase in the $0.2 \%$ proof stress may be explained by the solid solution hardening (T4) or the precipitation hardening (T6), respectively. The decrease in $0.2 \%$ proof stress at heat treatment temperature above $530^{\circ} \mathrm{C}$ is considered to be due to grain growth by the high-temperature solution treatment. The peak value of the $0.2 \%$ proof stress $(343 \mathrm{MPa})$ for the T6 sample heat-treated at $530^{\circ} \mathrm{C}$ was higher than that of the as-received sample (268 MPa) and the T6 sample heated by the EF (282 MPa). The fracture elongation is shown in Fig. 11. The change in fracture elongation with heat treatment temperature shows an almost opposite tendency to the proof stress, which is an ordinary relationship between the proof stress and the fracture elongation. The fracture elongation of T6 samples heat-treated at $530^{\circ} \mathrm{C}$ by the $\mathrm{IH}$ apparatus was slightly lower than that of the EF-treated sample. These experimental results for the proof stress and fracture elongation suggest

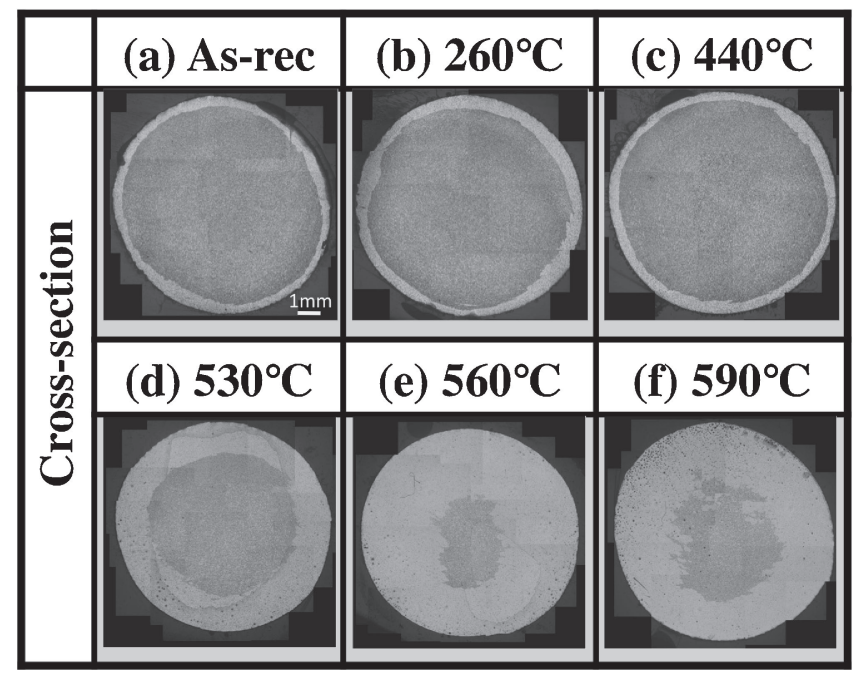

Fig. 12 Microstructure in the cross section for typical heat treatment temperatures.

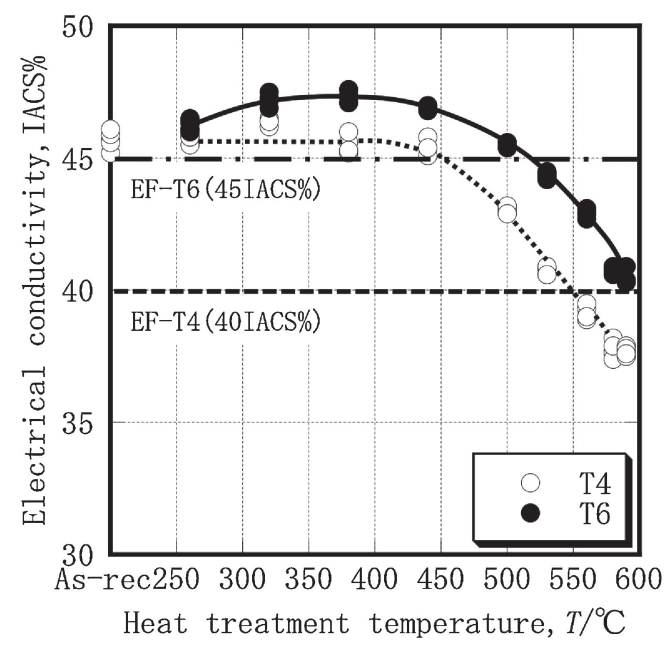

Fig. 13 Relationship between heat treatment temperature and electrical conductivity.

that the samples heat-treated by the IH apparatus had more precipitates than the EF-treated samples. The microstructure in the cross section is shown in Fig. 12 for the representative heat treatment temperatures. As shown, grain growth appeared in the near surface of the sample and when heat treatment was conducted above $560^{\circ} \mathrm{C}$, unstable grain growth almost reached the center of the cross section, which may be the cause of the decrease in proof stress and fracture elongation. On the other hand, there is no noticeable grain growth in the center region of the sample. The relationship between the heat treatment temperature and the electrical conductivity is presented in Fig. 13. Under T4 conditions, the conductivity of the sample heat-treated at above $440^{\circ} \mathrm{C}$ shows a significant decrease resulting from the increased amount of solid solute atoms in the matrix. In contrast, the samples after artificial aging treatment show a slightly higher value of conductivity compared with that before aging treatment. This increase in the conductivity may be due to the decrease in amount of solid solute atoms in the matrix accompanied by the formation of precipitates during the 


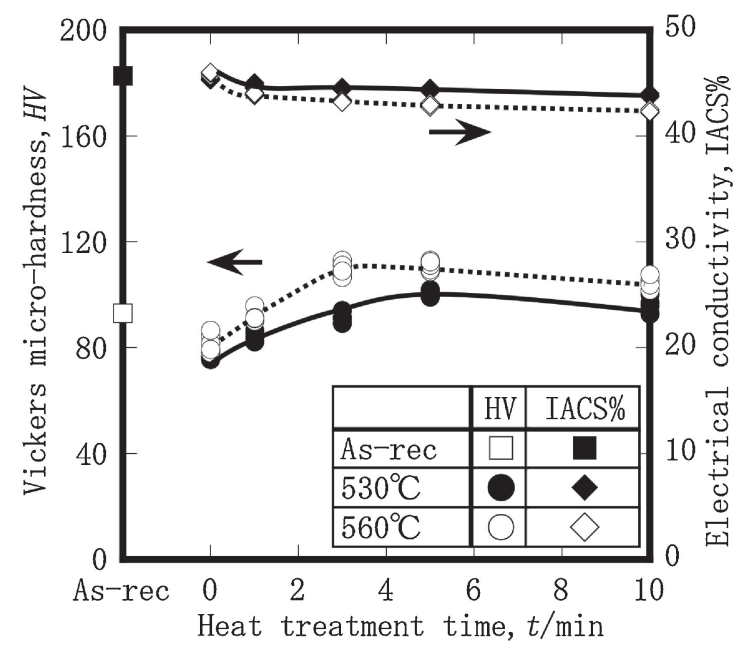

Fig. 14 Changes in Vickers hardness and electrical conductivity with heat treatment time after $\mathrm{T} 6$ treatment.

artificial aging. These changes in electrical conductivity with the heat treatment and aging treatment correspond to those of the hardness, proof stress and fracture elongation.

Therefore, the heat treatment using the IH apparatus is considered to be a useful technique for the heat treatment of heat-treatable aluminum alloys.

\subsection{Effect of heat treatment time}

Here, we discuss the effect of heat treatment time on the mechanical properties after the sample is heat-treated using the $\mathrm{IH}$ apparatus at a rapid heating rate of $21^{\circ} \mathrm{C} / \mathrm{s}$. The temperature profiles for various heat treatment times are omitted since the holding times should be easy to adjust based on the temperature profile shown in Fig. 8. Figure 14 shows the changes in Vickers hardness and electrical conductivity with the heat treatment times after T6 treatment. The hardness increased with increasing holding time during the heat treatment process and then decreased. The peak values were obtained at 3 and $5 \mathrm{~min}$ at $560^{\circ} \mathrm{C}$ and $530^{\circ} \mathrm{C}$, respectively. In contrast, the conductivity decreased slowly with the increase in holding time. These results indicate that the decomposition rate of precipitates is faster at $560^{\circ} \mathrm{C}$ than at $530^{\circ} \mathrm{C}$. Therefore, in the heat treatment at $560^{\circ} \mathrm{C}$, the required amount of solid solution atoms in the matrix for forming adequate precipitates may be secured within a short time. The changes in the $0.2 \%$ proof stress and the fracture elongation with holding time are shown in Fig. 15. As can be seen, the variations in $0.2 \%$ proof stress are almost the same as those in the hardness. The $0.2 \%$ proof stress of the heat treatment temperature at $530^{\circ} \mathrm{C}$ increased with the increase in holding time, reached a peak value $(343 \mathrm{MPa})$ at $5 \mathrm{~min}$ and then decreased. In contrast, the peak value (344 MPa) of the sample treated at $560^{\circ} \mathrm{C}$ was obtained in a short time of $3 \mathrm{~min}$. The higher proof stresses of heat-treated samples using the $\mathrm{IH}$ apparatus compared to that of as-received sample may be resulted from the suppression of grain growth due to the short time heating (see microstructure observation shown below).

\subsection{Effect of heating rate}

The effect of the heating rate on the mechanical properties was also investigated. Figure 16 shows the temperature

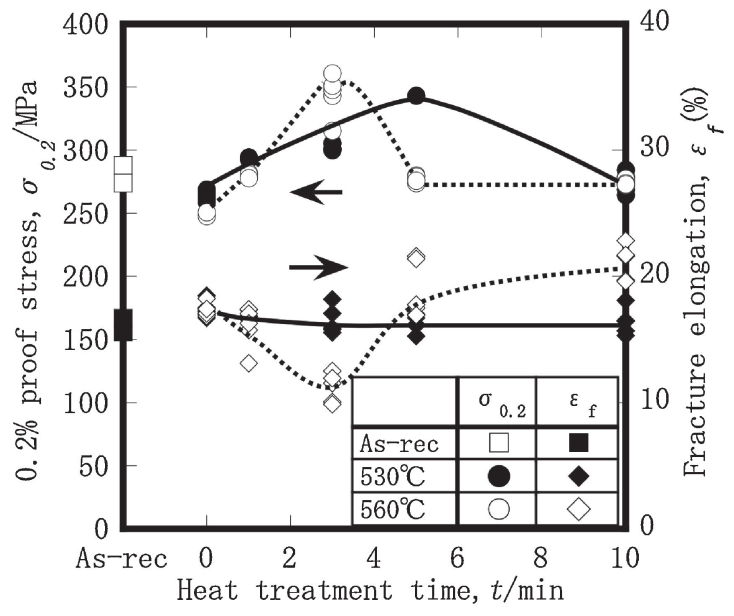

Fig. 15 Changes in $0.2 \%$ proof stress and fracture elongation with heat treatment time.

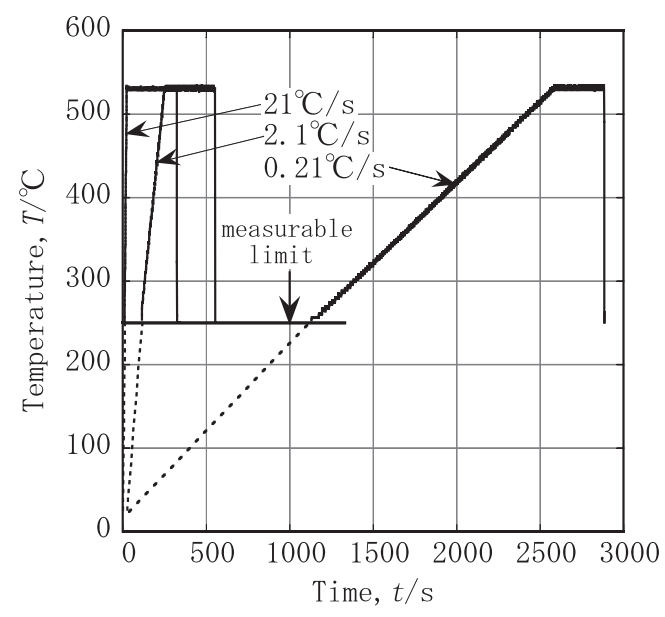

Fig. 16 Temperature profiles for three heating rates.

profiles for three heating rates. In all cases, the temperature increased linearly up to the heat treatment temperature of $530^{\circ} \mathrm{C}$ and the overheating immediately after rising to the heat treatment temperature was about $3-5^{\circ} \mathrm{C}$. In addition, the fluctuation in temperature was approximately $\pm 2-3^{\circ} \mathrm{C}$ in the holding process during the heat treatment. These results indicate that the heating rate is easy to adjust when using the IH apparatus for heat-treating aluminum alloys. Vickers hardness and electrical conductivity obtained after the T4 and T6 treatments are shown in Fig. 17 for the three heating rates. In the case of $21^{\circ} \mathrm{C} / \mathrm{s}$, the hardness after $\mathrm{T} 4$ and $\mathrm{T} 6$ treatments shows slightly higher values than those of 0.21 and $2.1{ }^{\circ} \mathrm{C} / \mathrm{s}$, while the conductivity is almost the same. From these results, the heating rate during the heat treatment process does not significantly affect the hardness and electrical conductivity.

Figure 18 shows the changes in $0.2 \%$ proof stress and fracture elongation with heating rate. The $0.2 \%$ proof stress and fracture elongation of the T6 sample heated at $21^{\circ} \mathrm{C} / \mathrm{s}$ were $343 \mathrm{MPa}$ and $17 \%$, respectively, which are nearly the same as those of $2.1^{\circ} \mathrm{C} / \mathrm{s}$ and $0.21^{\circ} \mathrm{C} / \mathrm{s}$. From these results, the mechanical properties are not significantly affected by the heating rate during the heat treatment process. Incidentally, 
the fracture elongation under T4 conditions increased gently with the rise in heating rate. The fractured surface was observed for the samples heat-treated at a heating rate of

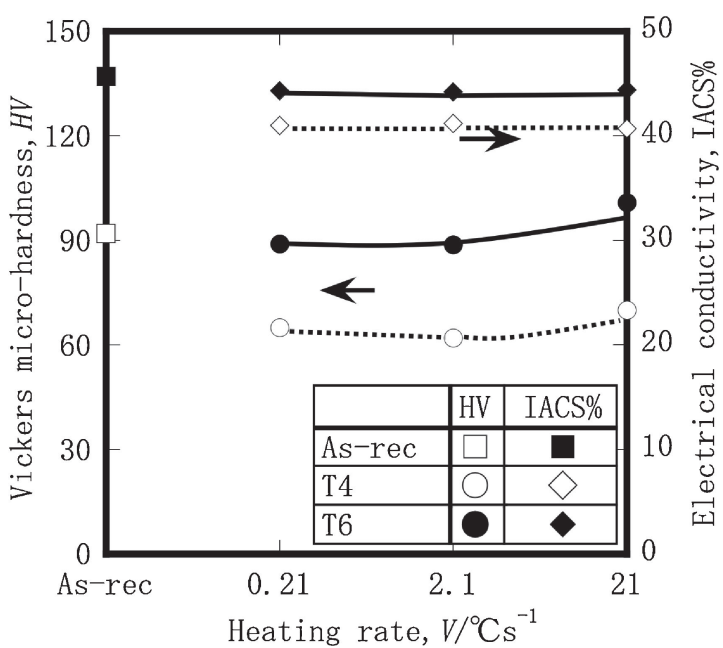

Fig. 17 Vickers hardness and electrical conductivity after T4 and T6 treatment for three heating rates.

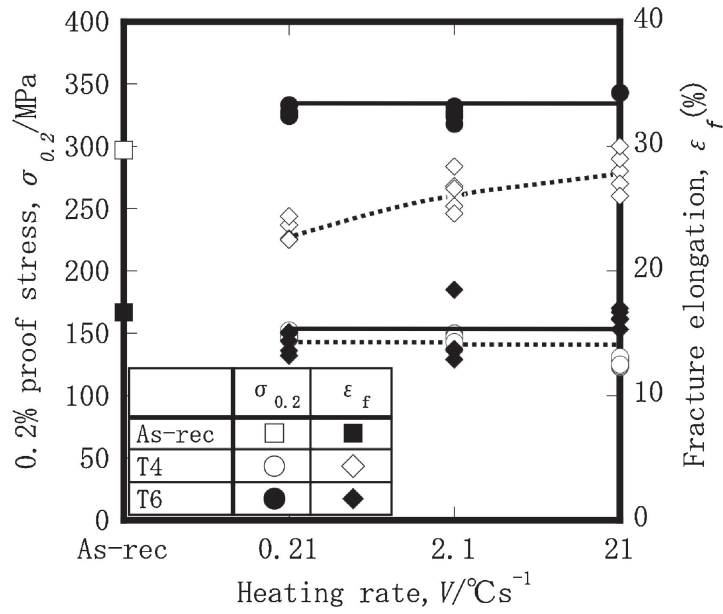

Fig. 18 Changes in $0.2 \%$ proof stress and fracture elongation with heating rate. $0.21^{\circ} \mathrm{C} / \mathrm{s}$ and $21^{\circ} \mathrm{C} / \mathrm{s}$. Figure 19 shows SEM micrographs of the fractured surface under T4 and T6 conditions. Many larger dimples were formed in the T6 samples, whereas smaller dimples were observed together with larger ones under T4 conditions. However, there is no significant difference in the fractured surface related to the heating rate during the heat treatment process. To investigate these microstructural features in detail, optical microscope images were taken of the cross section and inner section, and are shown in Fig. 20 for the as-received sample and samples heat-treated at various heating rates. As can be seen in the figure, the grain growth in the outer section is more clearly recognized for the samples heat-treated at various heating rates compared to the as-received sample. There is no significant difference in grain size in the inner section related to the heating rate during the heat treatment process. The same applies to grain growth in the outer section. Based on these results, it is concluded that the heating rate during the heat treatment process has little effect on the mechanical properties and microstructure of 6061 aluminum alloy.

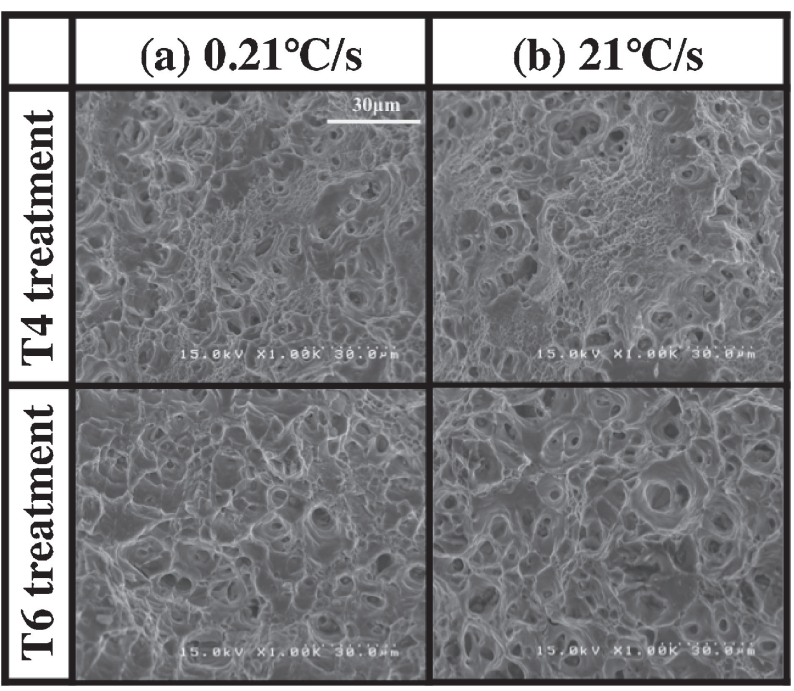

Fig. 19 SEM micrographs showing effect of heating rate on fracture surface after T4 and T6 treatment.

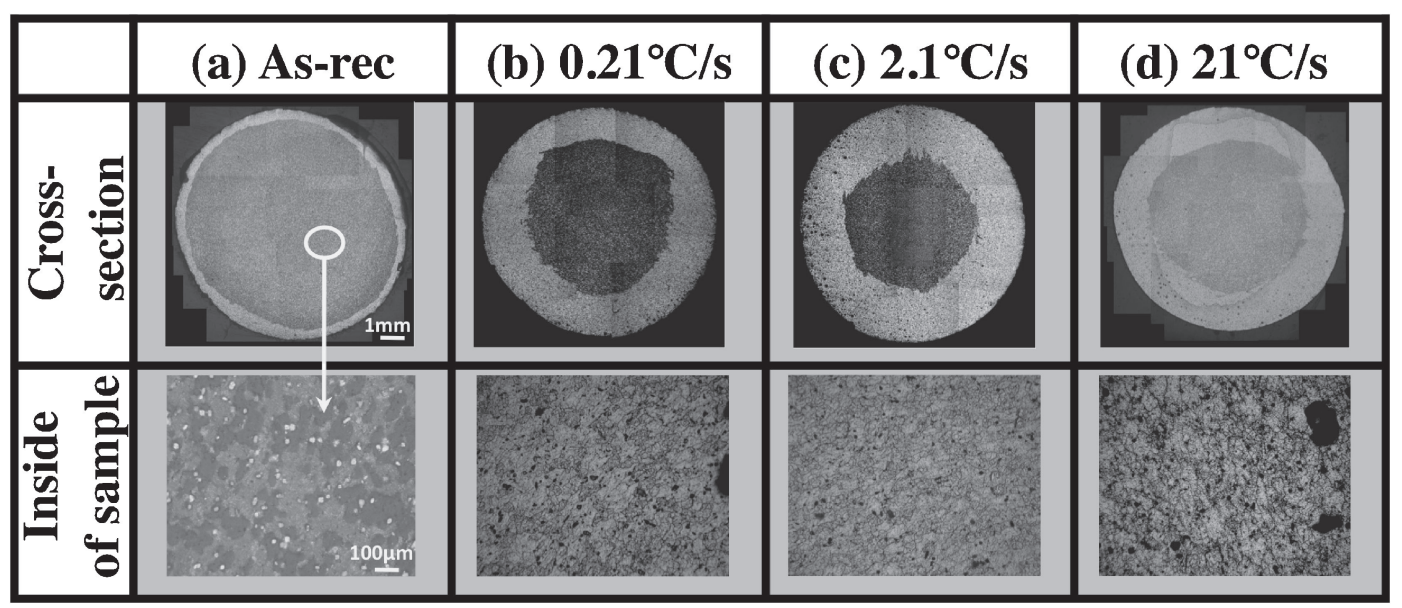

Fig. 20 Optical microscopic images showing microstructures in the cross section and inner section for three heating rates. 


\section{Conclusions}

A commercial 6061 aluminum alloy bar was subjected to heat treatment using a high-frequency induction heating apparatus in order to improve the mechanical properties and productivity. The results of this study are as follows:

(1) When the high-frequency induction heating apparatus is applied to the heat treatment of 6061 aluminum alloy bar, homogeneous heating of the sample can be performed; temperature differences in the length, width and depth directions were small, within $3.5^{\circ} \mathrm{C}$. Heat treatment using the induction heating apparatus achieved rapid linear heating of $21^{\circ} \mathrm{C} / \mathrm{s}$ in the heating process, overheating of about $4^{\circ} \mathrm{C}$ at the temperature transition stage from heating to holding processes and no significant temperature fluctuation $\left( \pm 3^{\circ} \mathrm{C}\right)$ in the holding process.

(2) The T6 sample heat-treated at $530^{\circ} \mathrm{C}$ for $5 \mathrm{~min}$ using the induction heating apparatus showed a higher $0.2 \%$ proof stress than the sample heat-treated for $30 \mathrm{~min}$ using the electric furnace.

(3) There was no significant change in hardness, $0.2 \%$ proof stress, fracture elongation or microstructure with heating rates ranging from 0.21 to $21^{\circ} \mathrm{C} / \mathrm{s}$. It is concluded that the heating rate during the heat treatment process scarcely influences the mechanical properties of 6061 aluminum alloy.

From these results, it is considered that the induction heating apparatus is effective for the heat treatment of heattreatable aluminum alloys.

\section{Acknowledgements}

This work was supported by Asakawa Netusyori Co., Ltd. and Marushin Heat Co., Ltd. for the technical analysis. Part of this study was funded by the Light Metal Educational Foundation, Inc.

\section{REFERENCES}

1) T. Irinouchi, H. Toda, T. Sakai, T. Kobayashi and L. Wang: J. JILM 55 (2005) 159-163.

2) T. Fukuta, D. Nakashima, J. Kouda, Y. Kuroshima, Y. Misaka and K. Kawasaki: Trans. Jpn. Soc. Mech. Eng. A 726 (2007) 285-291.

3) J. Komotori, M. Shimizu, Y. Misaka and K. Kawasaki: Int. J. Fatigue 23 (2001) S225-S230.

4) Y. Misaka, K. Kawasaki, H. Ikuta and T. Morita: Trans. Jpn. Soc. Mech. Eng. A 596 (2001) 1173-1179.

5) K. Fukazawa, M. Koizumi, J. Komotori, M. Shimizu, Y. Misaka and K Kawasaki: Jpn. Soc. Mech. Eng. A 654 (2001) 124-129.

6) T. Morita, W. Niwayama, K. Kawasaki and Y. Misaka: Trans. Jpn. Soc. Mech. Eng. A 624 (1998) 2115-2120.

7) T. Morita, Y. Misaka, K. Kawasaki and T. Iizuka: J. Jpn. Inst. Met. 68 (2004) 862-867.

8) I. Oku, M. Inokuma and K. Awai: J. JILM 40 (1990) 633-639.

9) K. Kaneshige and T. Araki: J. JILM 51 (2001) 209-211.

10) F. W. Curtis: High-Frequency Induction Heating, (McGraw-Hill, New York, 1950) pp. 9-20

11) F. Shang, E. Sekiya and Y. Nakayama: Collected Abstracts of the 2008 Autumn Meeting of the Jpn. Inst. Light Met., (2008) pp. 291-292.

12) The microstructure and property of aluminum alloy, (The Japan Institute of Light Metals, Tokyo, 1991) p. 285. 